\title{
Chronic Obstructive Pulmonary Disease and Bronchodilator Response: Does it Matter?
}

\author{
Donald P. Tashkin, MD
}

Emeritus Professor of Medicine, Division of Pulmonary and Critical Care Medicine, David Geffen School of Medicine at UCLA, Los Angeles, California, USA

\section{ABSTRACT}

A positive bronchodilator response is found in most patients with moderate-to-very-severe chronic obstructive pulmonary disease (COPD), although its presence varies over time within the same patient as well as across patients depending, in part, on the severity of the pre-bronchodilator level of airflow obstruction. Consequently, the response to a bronchodilator does not reliably distinguish COPD from asthma, although a particularly marked response suggests the presence of asthma/COPD overlap. The absence of an acute response to a bronchodilator in COPD does not preclude a favourable long-term response to maintenance bronchodilator therapy, although it may predict a reduced magnitude of the long-term response. Bronchodilator responsiveness does not appear to define a distinct phenotype of COPD or predict most clinically meaningful outcomes. However, performing spirometry after a bronchodilator may have practical utility in clinical practice as an indicator of the maximum ("ceiling") lung function that patients are capable of attaining as a goal to attempt to achieve with pharmacotherapy. (BRN Rev. 2018;4(3):200-13)

Corresponding author: Donal P. Tashkin, dtashkin@mednet.ucla.edu

Key words: Asthma. Asthma/Chronic obstructive pulmonary disease. Bronchodilator response. Chronic obstructive pulmonary disease (COPD). 


\section{INTRODUCTION}

The question whether the response to a bronchodilator matters with regard to chronic obstructive pulmonary disease (COPD) depends somewhat on whether the response is being considered as important for the following: 1) diagnosing COPD; 2) differentiating COPD from asthma or identifying an overlap of asthma with COPD (ACO); 3) assessing the severity of COPD; 4) examining the course of COPD in population-based and interventional studies; 5) predicting the long-term effectiveness of treatment based on an initial assessment of shortterm bronchodilator responsiveness; and/or 6) classifying COPD patients into a distinct phenotype that has implications with regard to predicting meaningful clinical outcomes. This article builds on previous reviews of bronchodilator reversibility in COPD ${ }^{1,2}$ by focusing specifically on the question whether the response to a bronchodilator matters.

\section{DEFINITION OF A “POSITIVE" BRONCHODILATOR RESPONSE AND FACTORS AFFECTING ITS DETECTION}

Before addressing each of the aforementioned considerations, it is important first to define what is meant by a "positive", "meaningful" or "significant" bronchodilator response, as well as the limitations of this definition. According to the American Thoracic Society (ATS)/European Respiratory Society (ERS) Task Force on Standardization of Lung Function Testing, the response to a bronchodilator is considered positive if either the forced expiratory volume in one second $\left(\mathrm{FEV}_{1}\right)$ and/or the forced vital capacity (FVC) increases by $\geq 12 \%$ and/or $\geq 200 \mathrm{ml}$ compared to the pre-bronchodilator value ${ }^{3}$. Although a positive bronchodilator response has also been defined by a $15 \%$ increase over the pre-bronchodilator $\mathrm{FEV}_{1}$ independent of a volume increase of $200 \mathrm{ml}$, the ATS/ERS definition has the advantage of including an absolute volume threshold since patients with more severe disease may meet the $15 \%$ increase threshold due to a "low denominator" effect, while failing to meet the absolute volume threshold. Regardless of the definition used, however, it is well recognised that the bronchodilator response of an individual patient can vary depending on the dose of the bronchodilator used, the class of bronchodilator (beta ${ }_{2}$-agonist versus muscarinic antagonist), the method of delivery (pressurised metered dose inhaler [pMDI] with or without a spacer or a nebulizer) and the time interval between administration of the inhaled bronchodilator and performance of post-bronchodilator spirometry ${ }^{4}$. While administration of four separate inhalations of a short-acting beta ${ }_{2}$-agonist (e.g, salbutamol $100 \mathrm{mcg}$ per actuation) has been recommended ${ }^{3}$, lower doses are often used in practice. Moreover, although a 15-minute delay between administration of the bronchodilator and performance of the post-bronchodilator spirometry has also been recommended ${ }^{3}$, the peak bronchodilator response may not be achieved until as long as 1-2 hours after the bronchodilator is inhaled ${ }^{4}$. It has also been shown that the response to a bronchodilator in individual patients varies considerably over time $\mathrm{e}^{1,5}$. For example, in one study $52 \%$ of patients who initially did not exhibit a positive response (defined by a $10 \%$ predicted improvement in $\mathrm{FEV}_{1}$ ) changed their responsiveness (from negative to positive responses or vice versa) on repeated testing on different days ${ }^{1}$ (Fig. 1). In the more recent observational study Evaluation 


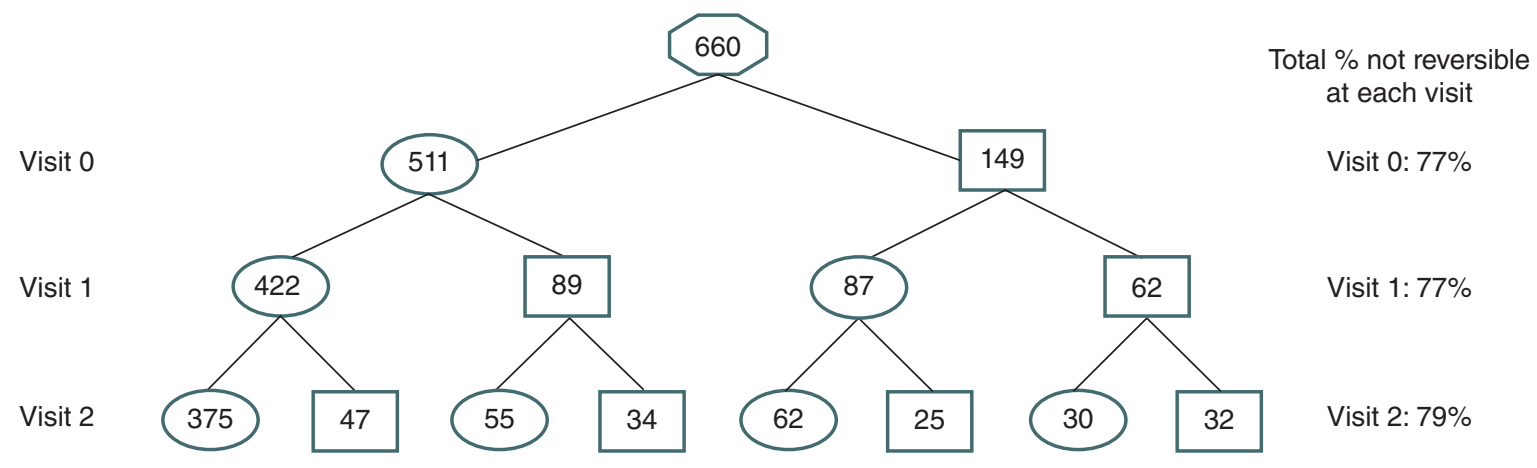

Reversible

No reversible

FiguRE 1. Changes in responder classification (reversible versus not reversible) at each visit after bronchodilators using American Thoracic Society criteria (reproduced with permission from Calverley PM et al. ${ }^{1}$.

of COPD Longitudinally to Identify Predictive Surrogate End-points (ECLIPSE) of 1831 patients with COPD in whom reversibility was assessed $15 \mathrm{~min}$ after administration of $400 \mu \mathrm{g}$ salbutamol on four separate occasions, only $16 \%$ of subjects who were reversible at the first visit met reversibility criteria on all follow-up visits, while $66 \%$ who were irreversible initially remained irreversible at all subsequent visits ${ }^{5}$.

Likely reasons for this variability in responder status over time include the between-test variability in the $\mathrm{FEV}_{1}$ measurement itself, the between-day variation in bronchomotor tone and the only small change that is sometimes required to move between response categories. Another source of variation in evaluating responsiveness is the class or classes of bronchodilator used (beta ${ }_{2}$-agonist, muscarinic antagonist or both combined) $)^{6,7}$. Some COPD patients appear to respond preferentially to a short-acting beta $_{2}$-agonist, while others to a short-acting muscarinic antagonist ${ }^{6}$. Pharmacogenetic data from Japan suggest that the preferential response to the two different classes of short-acting bronchodilators may be determined by beta ${ }_{2}$-adrenergic polymorphisms ${ }^{8}$. An additional source of variation in bronchodilator responsiveness is the baseline severity of airflow obstruction. For example, the flow response $\left(\mathrm{FEV}_{1}\right)$ has been shown to be generally poor in patients with mild-to-moderate airflow obstruction', greatest in those with moderate obstruction ${ }^{10,11}$ (Table 1) and progressively smaller with increasing severity of obstruction. In contrast, the volume response appears to be somewhat equivalent across different grades of severity from moderate-to-very-severe, such that the most severely obstructed patients (i.e., those most likely to be hyperinflated ${ }^{12}$ ) tend to be predominantly volume responders while only moderately obstructed patients tend to be predominantly flow responders ${ }^{10}$ (Table 1 ). In this regard, in studies reporting the proportion 
TABLE 1. Proportion of COPD patients achieving increases in $\mathrm{FEV}_{1}$ and $\mathrm{FVC}$ of $\geq 12 \%$ and $\geq 200 \mathrm{ml}$ in the Understanding Potential Long-term Impacts on Function with Tiotropium (UPLIFT) trial ${ }^{10}$

\begin{tabular}{|l|c|c|c|}
\hline GOLD Grade & $\begin{array}{c}\mathbf{2} \\
\text { Moderate } \\
(\%)\end{array}$ & $\begin{array}{c}\mathbf{3} \\
\text { Severe } \\
(\%)\end{array}$ & $\begin{array}{c}\mathbf{4} \\
\text { Very severe } \\
(\%)\end{array}$ \\
\hline FEV 1 & 65 & 49 & 20 \\
\hline FVC & 58 & 67 & 68 \\
\hline
\end{tabular}

$\mathrm{FEV}_{1}$ : forced expiratory volume in one second; FVC: forced vital capacity.

of COPD patients who respond positively to a bronchodilator, primary emphasis is usually placed on the flow response and the volume response is often ignored. This is unfortunate since a positive volume response implies reductions in gas trapping and lung hyperinflation, features that contribute at least as importantly to exercise limitation and exertional dyspnoea as airflow obstruction ${ }^{13}$.

\section{DIAGNOSING CHRONIC OBSTRUCTIVE PULMONARY DISEASE}

A defining feature of COPD according to the Global Initiative for Chronic Obstructive Lung Disease (GOLD) is the presence of airflow obstruction that is "not fully reversible", i.e., only "partially" reversible, in response to a bronchodilator ${ }^{14}$. Consequently, to fulfil the GOLD definition of COPD, a patient clinically suspected of having COPD with demonstrated airflow obstruction on pre-bronchodilator testing should undergo repeat spirometry after a bronchodilator is administered to exclude complete reversibility (i.e., a change for an $\mathrm{FEV}_{1} / \mathrm{FVC}<0.70$ to an $\mathrm{FEV}_{1} / \mathrm{FVC}>0.70$ ), which, if present, would favour a diagnosis of asthma rather than COPD. Aside from the considerable debate as to the spirometric definition of airflow obstruction using a fixed ratio threshold $\left(\mathrm{FEV}_{1} / \mathrm{FVC}<0.70\right)$ versus the lower limit of normal (LLN) regarding misclassification of airflow obstruction with the fixed ratio ${ }^{15-19}$ due largely to the impact of age on the latter, there is also some controversy as to the need to determine the post-bronchodilator $\mathrm{FEV}_{1} / \mathrm{FVC}$ ratio in patients with a reduced pre-bronchodilator $\mathrm{FEV}_{1} / \mathrm{FVC}$. In this regard, Mannino et al. ${ }^{19}$ argue that most longitudinal databases of COPD patients have not included post-bronchodilator lung function measurements, so that population-based studies of COPD outcomes (e.g., mortality and lung cancer) have largely relied on the pre-bronchodilator $\mathrm{FEV}_{1} / \mathrm{FVC}$ ratio $^{20-24}$. Moreover, using data from the Lung Health Study (LHS), Mannino et al. ${ }^{25}$ have shown that both pre- and post-bronchodilator lung function predicted mortality with similar accuracy; however, all LHS patients had to have a reduced post-bronchodilator $\mathrm{FEV}_{1} / \mathrm{FVC}$ to be eligible to participate in the study. Interestingly, $8.5 \%$ of Genetic epidemiology of COPD (COPDGene) subjects had a reduced pre- but normal post-bronchodilator $\mathrm{FEV}_{1} / \mathrm{FVC}$ ratio and $3 \%$ of the subjects had a normal pre- but reduced post-bronchodilator ratio, largely due to a post-bronchodilator increase in $\mathrm{FVC}^{26}$. Interestingly, however, obstruction defined by either or both pre- and post-bronchodilator ratios showed similar associations with symptoms of chronic bronchitis and dyspnoea, reduced exercise capacity and percentage of emphysema and gas trapping on high-resolution computed tomography (HRCT), suggesting a similar burden of disease irrespective of the bronchodilator response in this subject population. On the other hand, obstruction on both pre- and post-bronchodilator spirometry showed a stronger association with exacerbations than obstruction on the post- or pre-bronchodilator test 
alone and only post-bronchodilator obstruction was associated with increased mortality ${ }^{26}$.

In view of the above considerations, it is not entirely clear to what extent defining COPD by the pre- versus post-bronchodilator $\mathrm{FEV}_{1} / \mathrm{FVC}$ ratio truly matters. What complicates this debate even further is the finding that many current and former cigarette smokers with preserved spirometry, namely a normal pre-bronchodilator $\mathrm{FEV}_{1} / \mathrm{FVC}$ ratio, have chronic respiratory symptoms according to the COPD Assessment Test (CAT) compared with non-smokers and that these individuals have COPD-like findings on HRCT (gas trapping and/or visual evidence of emphysema), are often prescribed medication for COPD and develop exacerbations and acute worsening of symptoms requiring additional medication ${ }^{27-30}$. It is likely that these individuals may proceed to develop overt COPD as defined spirometrically.

\section{DIFFERENTIATING CHRONIC OBSTRUCTIVE PULMONARY DISEASE FROM ASTHMA/CHRONIC OBSTRUCTIVE PULMONARY DISEASE OVERLAP}

Historically, COPD was considered to be characterised by irreversible airflow obstruction, as distinguished from asthma in which reversible bronchospasm or increased airways reactivity in response to bronchoconstrictor stimuli is a defining feature. Because of this perception, bronchodilator responsiveness has been suggested as a feature that might distinguish between asthma and COPD ${ }^{31}$. On the other hand, several studies have demonstrated that a large proportion of patients with COPD without features suggestive of asthma other than responsiveness to a bronchodilator exhibit a positive response to a bronchodilator (or combination of bronchodilators) $)^{7,10}$. As a consequence of these findings, a component of the current characterisation of COPD is the frequent presence of "partially" or "not fully" reversible airflow obstruction while the relevance of the response to a bronchodilator as a means of distinguishing between asthma and COPD has been downplayed. In addition, $16-25 \%$ and $33-43 \%$ of patients with well-established mild-to-moderate or moderate-to-severe asthma, respectively, have been shown to have a "fixed" component of airflow obstruction defined by an $\mathrm{FEV}_{1} / \mathrm{FVC}$ ratio $<$ LLN or $<0.70$ that fails to improve above the LLN or above 0.70 in response to a bronchodilator $^{32,33}$, at least when tested on a single occasion. With therapy including inhaled glucocorticoids (ICS), full reversibility is restored in some, but not all, of these patients ${ }^{34}$.

The increasing recognition that some patients with COPD or asthma have features of both diseases has led to the characterisation of these patients as having ACO, or asthma-COPD overlap ${ }^{35,36}$. Although some have characterised this condition as a syndrome, others argue that ACO, like COPD and asthma alone, is a heterogeneous spectrum of disorders with varying phenotypic features and underlying pathophysiology and discourage applying the term "syndrome". Although there is no real consensus regarding a definition of $\mathrm{ACO}$, different groups have proposed diagnostic criteria ${ }^{37-40}$. A minor criterion in most of the proposed definitions is the presence of significant bronchodilator reversibility $(\geq 12 \%$ and $\geq 200 \mathrm{ml}$ increase in $\mathrm{FEV}_{1}$ ) on 2 or more occasions and a major criterion is the presence of marked reversibility with bronchodilators $(\geq 15 \%$ and $\geq 400 \mathrm{ml}$ increase in $\left.\mathrm{FEV}_{1}\right)^{34-37}$. A problem with the proposed minor criterion is that patients 
with well-defined COPD frequently exhibit this level of bronchodilator reversibility on $\geq 2$ occasions ${ }^{1,6,7}$, while marked reversibility (the major criterion) is distinctly uncommon in COPD. In the Understanding Potential Longterm Impacts on Function with Tiotropium (UPLIFT) trial, however, about $15 \%$ of patients exhibited this marked response ${ }^{10}$ (Fig. 2), but this response was to high doses of two different classes of bronchodilators with timing of the post-bronchodilator spirometry to match the expected peak action of each bronchodilator class ${ }^{41}$. Of course, it is also possible that the $15 \%$ of the UPLIFT patients who exhibited a particularly marked bronchodilator response might have had ACO. Interestingly, according to a systematic literature review of ACO in patients with COPD, the reported prevalence has varied from $12.1 \%$ to $55.2 \%{ }^{42}$, most likely reflecting varying diagnostic criteria for both $\mathrm{COPD}$ and $\mathrm{ACO}$ and varying population characteristics, such as age, sex and smoking. A currently unmet need is to obtain a better understanding of the clinical, phenotypic and endotypic characteristics of $\mathrm{ACO}$, including its prevalence, natural history, pathophysiology and response to treatment. Since existing studies of treatment responses in COPD and in asthma exclude patients with features of both diseases, no information is currently available concerning optimal therapy for patients with $\mathrm{ACO}$, underscoring the importance of arriving at a consensus for defining this disorder.

\section{ASSESSING THE SEVERITY OF CHRONIC OBSTRUCTIVE PULMONARY DISEASE}

According to the 2007 GOLD report, the severity of airflow obstruction (mild, moderate, severe and very severe) was defined by the post-bronchodilator $\mathrm{FEV}_{1}$ percentage predicted $(\geq 80 \%, 50-79 \%, 49-30 \%$ and $<30 \%$, respectively) ${ }^{43}$, a definition that has been applied to entry criteria for clinical trials in which the target population comprises patients with specified degrees of spirometric severity of obstruction. In the 2011 GOLD report, the severity of airflow obstruction as thus defined was incorporated into an algorithm whereby recommendations for treatment with different classes of pharmacologic agents for patients with stable COPD were tied to a combination of respiratory symptom burden, level of obstruction and history of exacerbations ${ }^{44}$. This treatment algorithm was modified in the 2017 report to eliminate severity of airflow obstruction since the latter has been shown to be poorly correlated with symptoms, exercise tolerance and health-related quality of life, so that the only remaining features guiding recommended therapeutic options are symptom level and exacerbation risk ${ }^{14}$. On the other hand, in a small single-centre study of 300 consecutively seen Taiwanese patients with COPD, severity defined by the postbronchodilator $\mathrm{FEV}_{1}$ percentage predicted was an independent predictor of mortality in multivariate analysis, whereas pre-bronchodilator $\mathrm{FEV}_{1}$ predicted was not ${ }^{45}$. Moreover, the postbronchodilator percentage predicted $\mathrm{FEV}_{1}$ was more strongly correlated than the pre-bronchodilator value with all other studied outcome predictors, including body mass index (BMI), modified Medical Research Council (mMRC) scale, performance status (using the Eastern Cooperative Oncology Group [ECOG] questionnaire) and hospitalisation for an acute COPD exacerbation ${ }^{45}$. Further studies comparing the degree of severity of airflow obstruction defined by the pre- versus post-bronchodilator percent predicted $\mathrm{FEV}_{1}$ as a predictor of outcomes in COPD are warranted. 


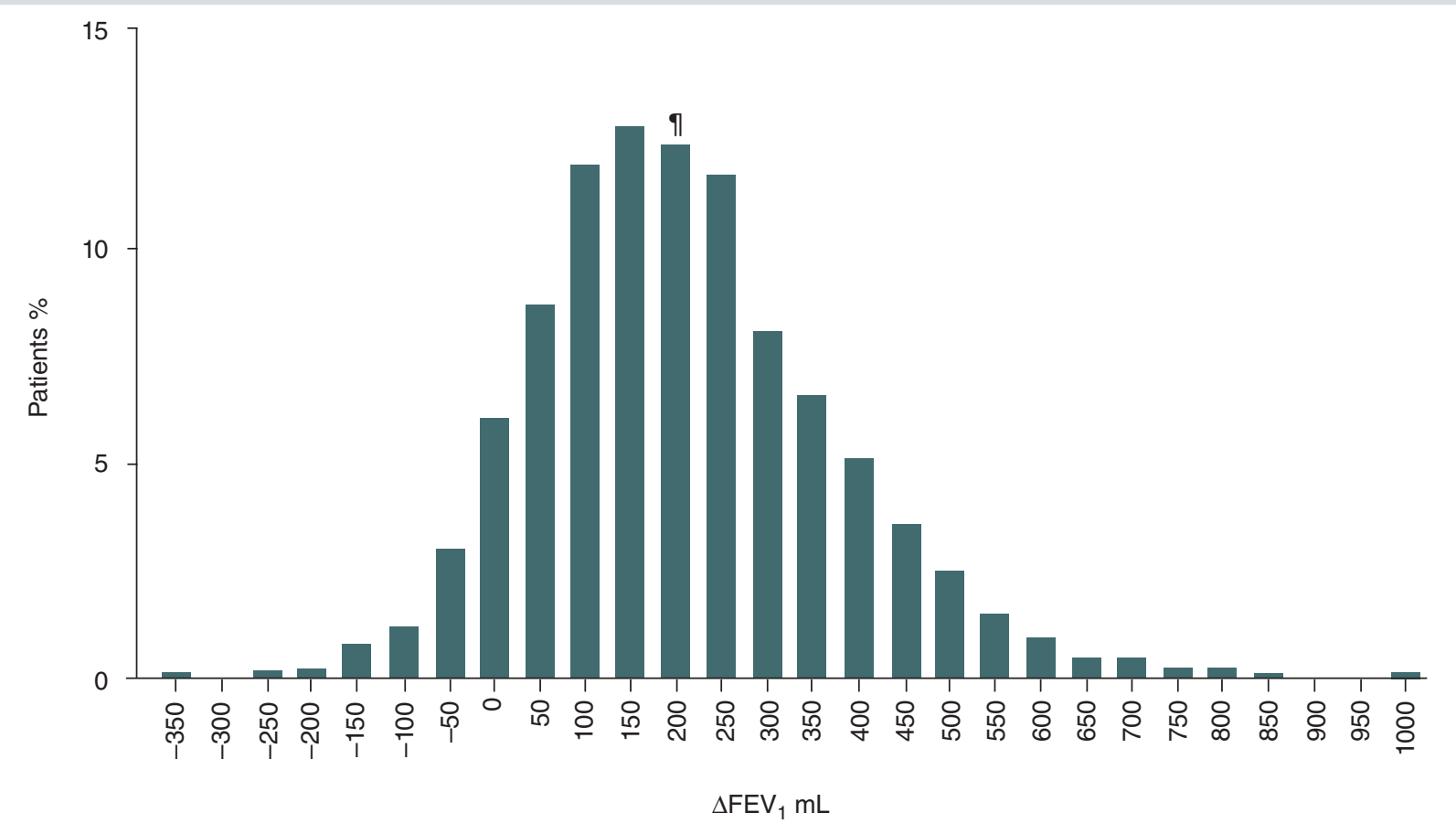

Figure 2. Proportion of patients $(\mathrm{n}=5656)$ showing absolute changes $(\mathrm{ml})$ in pre- to post-bronchodilator forced expiratory volume in one second $\left(\mathrm{FEV}_{1}\right)$ (reproduced with permission from Tashkin DP et al. ${ }^{10}$ ).

ๆ $55 \%$ showed a $\geq 200 \mathrm{ml}$ increase in FEV1; approximately $15 \%$ showed a $\geq 400 \mathrm{ml}$ increase in $\mathrm{FEV}_{1}$.

\section{EXAMINING THE COURSE OF CHRONIC OBSTRUCTIVE PULMONARY DISEASE IN OBSERVATIONAL AND INTERVENTIONAL STUDIES}

Numerous observational and interventional studies have measured the annual rate of change in $\mathrm{FEV}_{1}$ as a marker of COPD progression. In contrast to most previous observational studies, the landmark Lung Health Study I, in which the impact of early intervention on the annual rate of decline in $\mathrm{FEV}_{1}$ was investigated in smokers with mild-to-moderate airflow obstruction over a 5-year period, chose the post-bronchodilator $\mathrm{FEV}_{1}$ over the pre-bronchodilator value to chart the course of lung function decline ${ }^{47}$. Subsequent intervention trials of potentially disease-modifying therapy over the ensuing 25 years have also utilis ed the post-, rather than the pre-, bronchodilator $\mathrm{FEV}_{1}$ to delineate the progression of $\mathrm{COPD}^{48-55}$. The rationale for the choice of the post- over the pre-bronchodilator $\mathrm{FEV}_{1}$ for this purpose has not been clearly articulated but may have derived from the belief that the post- may be less variable than the pre-bronchodilator $\mathrm{FEV}_{1}$ or that it would be less influenced by failure to adhere to instructions to withhold any bronchodilator medication during the prescribed washout period prior to spirometric testing. However, using data from 4484 participants in the Lung Health Study with pre- and post- bronchodilator measurements we showed that the variability of 
the mean $\mathrm{FEV}_{1}$ at each annual visit was slightly greater for the post- than the pre-bronchodilator value, while estimates for the slope of $\mathrm{FEV}_{1}$ decline using a random coefficient model that included time, sex, age, BMI, methacholine reactivity and baseline smoking intensity were similar ${ }^{56}$. These findings imply that serial measurements of the pre-bronchodilator $\mathrm{FEV}_{1}$ are generally adequate for comparing the effect of different interventions on the trajectory of $\mathrm{FEV}_{1}$ over time at least in COPD subjects with mild-to-moderate airflow obstruction.

On the other hand, in patients with moderate-to-very severe airflow obstruction participating in the 4-year UPLIFT trial, the slope of the post-bronchodilator $\mathrm{FEV}_{1}$ (estimated using a linear mixed effects model that adjusted for height, sex, smoking status, baseline percentage predicted $\mathrm{FEV}_{1}$ and baseline bronchodilator response) was significantly steeper than the pre-bronchodilator slope regardless of treatment arm (tiotropium versus placebo) $)^{57}$ (Fig. 3), while the estimated variances of the pre- and post-bronchodilator slopes were similar. These slope differences need to be taken into consideration in evaluating the impact of an intervention on the annual rate of change in $\mathrm{FEV}_{1}$ in response to an intervention since the effect of the intervention might vary depending on whether the change was defined by the pre- versus the post-bronchodilator measurement.

If the acute response to a bronchodilator declined over time, this could possibly explain the steeper post- versus pre-bronchodilator slope of $\mathrm{FEV}_{1}$ observed in the UPLIFT study. In support of this hypothesis, further analysis of data from this long-term trial revealed progressive and highly significant mean declines in the $\mathrm{FEV}_{1}$ (as well as the FVC) response to bronchodilator administration as the subjects aged $(p<0.0001)^{58}$ (Fig. 4). Similar findings had been observed in the Clinical Study of Intermittent Positive Pressure Breathing (IPPB) when the bronchodilator response was reported as change in the percentage predicted $\mathrm{FEV}_{1}{ }^{59}$. In the UPLIFT trial participants, moreover, the declines in both the $\mathrm{FEV}_{1}$ and $\mathrm{FVC}$ bronchodilator responses were generally larger in patients with severe-to-very severe (GOLD grades 3/4) than mild-to-moderate (GOLD grades 1/2) airflow obstruction, in older patients ( $>65$ years of age) and in former compared to current smokers ${ }^{57}$. The observed declines in bronchodilator responsiveness over time parallel the usually progressive age-related decline in lung function that is typical of COPD ${ }^{14,46,60}$, suggesting an inter-relationship between these two phenomena. Although speculative, a possible mechanism contributing to these age-related declines in the $\mathrm{FEV}_{1}$ response to a bronchodilator is the progressively increased thickness of the walls of the small airways with increasing severity of airflow obstruction, as demonstrated by Hogg et al. ${ }^{61}$. Since the increasing wall thickness with decreasing $\mathrm{FEV}_{1}$ is likely to be accompanied by a decrease in airway wall compliance, this effect would be to attenuate the increase in airway luminal patency (and thus in $\mathrm{FEV}_{1}$ ) in response to bronchodilator-induced airway smooth muscle relaxation.

Another possible explanatory mechanism for the diminution of both $\mathrm{FEV}_{1}$ and FVC responses to a bronchodilator with age is the loss of lung elasticity with age $\mathrm{e}^{62}$ that is likely to increase dynamic airway compression, 

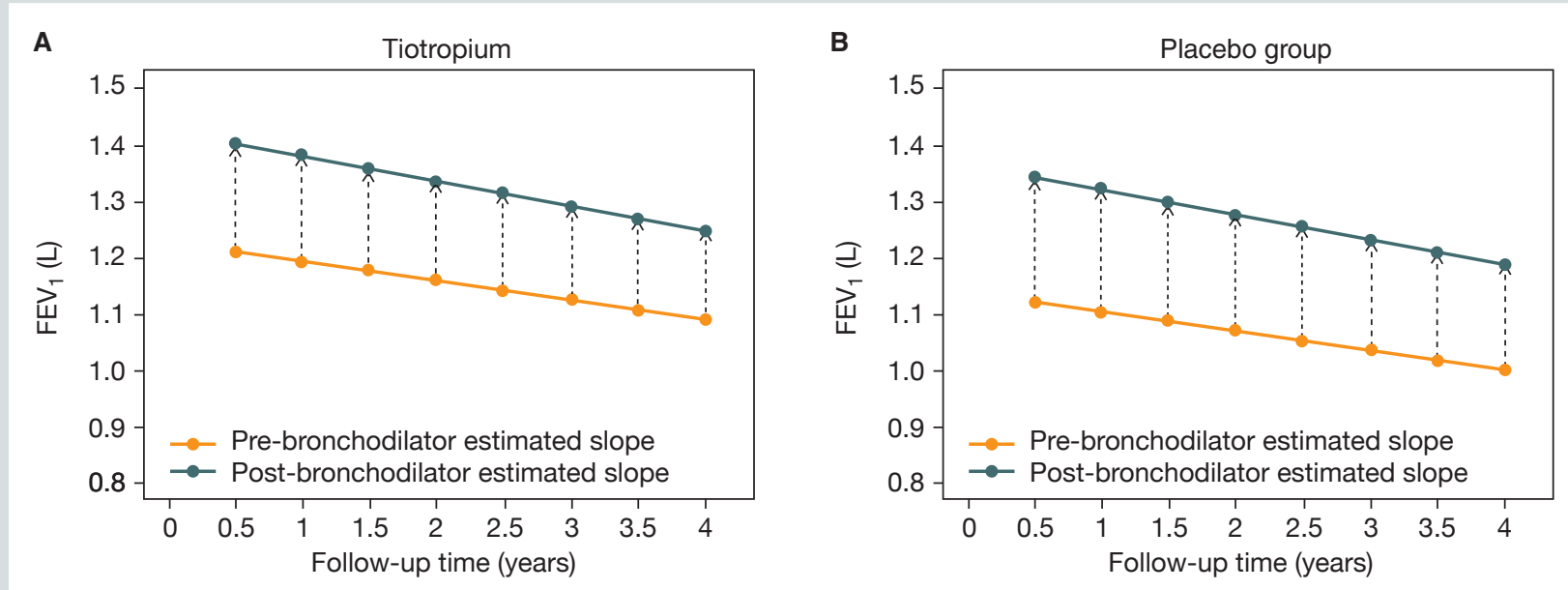

FIGURE 3. Estimated slopes of annual decline in pre- and post-bronchodilator FEV ${ }_{1}$ in the tiotropium (A) and placebo (B) groups during the 4-year Understanding Potential Long-term Impacts on Function with Tiotropium (UPLIFT) trial (reproduced with permission from Tashkin DP57 et al.). $\mathrm{FEV}_{1}$ : forced expiratory volume in one second.
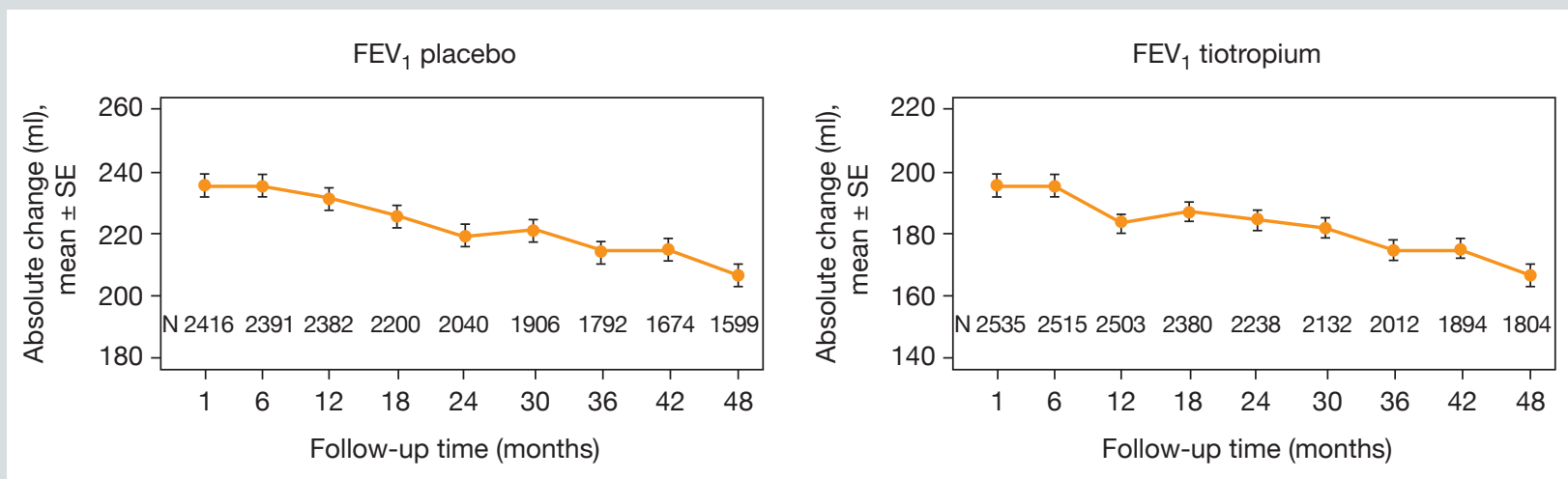

FVC placebo
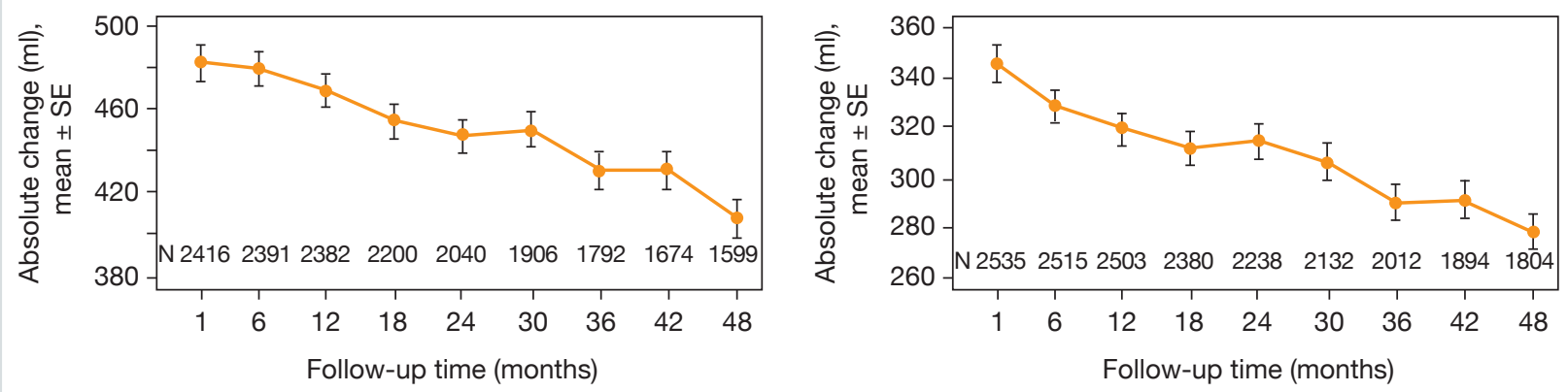

Figure 4. Mean absolute bronchodilator responses $( \pm S D)$ over 4 years by Understanding Potential Long-term Impacts on Function with Tiotropium (UPLIFT) treatment group (placebo and tiotropium) (reproduced with permission from Tashkin DP57).

$\mathrm{FEV}_{1}$ : forced expiratory volume in one second; FVC: forced vital capacity; N: number of individuals; SD: standard deviation. 
thereby counteracting drug-induced bronchodilation and reduction in gas trapping. Regardless of the underlying mechanism, from a clinical perspective the declines in bronchodilator responsiveness with aging might result in a general loss of clinical efficacy of bronchodilator therapy over time.

\section{PREDICTING THE LONG-TERM EFFECTIVENESS OF MAINTENANCE BRONCHODILATOR TREATMENT BASED ON AN INITIAL ASSESSMENT OF SHORT-TERM BRONCHODILATOR RESPONSIVENESS}

Several older studies have suggested that the acute or initial response to a short- or long-acting bronchodilator may not be predictive of the long-term response to a long-acting bronchodilator ${ }^{63,66}$. For example, Mahler and al. ${ }^{63}$ studied the 12-hour $\mathrm{FEV}_{1}$ responses over 12 weeks to salmeterol bid, ipratropium qid and placebo in 411 COPD patients with moderate-to-very-severe airflow obstruction stratified by positive or negative bronchodilator reversibility categories based on their screening response to albuterol, a positive responder status being defined as an increase in $\mathrm{FEV}_{1}$ of $\geq 12 \%$ and $\geq 200 \mathrm{ml}$ over the pre-bronchodilator value 30 minutes after administration of $180 \mu \mathrm{g}$ albuterol $^{63}$. Although the 12 -week $\mathrm{FEV}_{1}$ responses to both salmeterol and ipratropium compared to placebo were significantly higher in the positive responder than the non-responder group, they were still significantly higher versus placebo in the non-responder group, and the $\mathrm{FEV}_{1}$ responses to both active agents over placebo were noticeably higher on the last study day (12 weeks) compared to the day of randomisation.
Similar results were obtained by Rennard et al. ${ }^{64}$ in 405 patients in a similarly designed study in which the responders had a greater benefit from salmeterol than the non-responders, but the non-responders also exhibited a significant benefit compared to placebo, albeit of lesser magnitude compared to that experienced by the responders. Post-hoc analysis of data from two one-year randomised controlled trials of the long-acting muscarinic antagonist, tiotropium, versus placebo in 921 patients with moderate-to-very-severe COPD was performed to determine whether long-term improvements in lung function and health-related quality of life were associated with short-term improvements in $\mathrm{FEV}_{1}$ measured on the first day of the study ${ }^{66}$. Patients assigned to tiotropium were stratified for purposes of analysis into good responders and poor responders to tiotropium on the first study day, good responders being defined as those who exhibited $\mathrm{a} \geq 12 \%$ and $\geq 200 \mathrm{ml}$ improvement in $\mathrm{FEV}_{1}$ compared to baseline within 120 minutes after the initial dose of tiotropium. Both the good responders and poor responders to tiotropium on the first day of the trial showed significant 1-year improvements not only in $\mathrm{FEV}_{1}$, but also in reduction in rescue inhaler use, dyspnoea (Transition Dyspnoea Index [TDI]) and healthrelated quality of life ([HRQoL] St. George's Respiratory Questionnaire), compared to patients in the placebo arm. However, the magnitude of improvements after one year was greater in the first-day tiotropium responders than the poor tiotropium responders (Fig. 5). These findings complement those using a longacting beta-agonist and imply that the shortterm response to either a rapid-acting or longacting bronchodilator should not be used as a criterion for prescribing long-term bronchodilator treatment. 

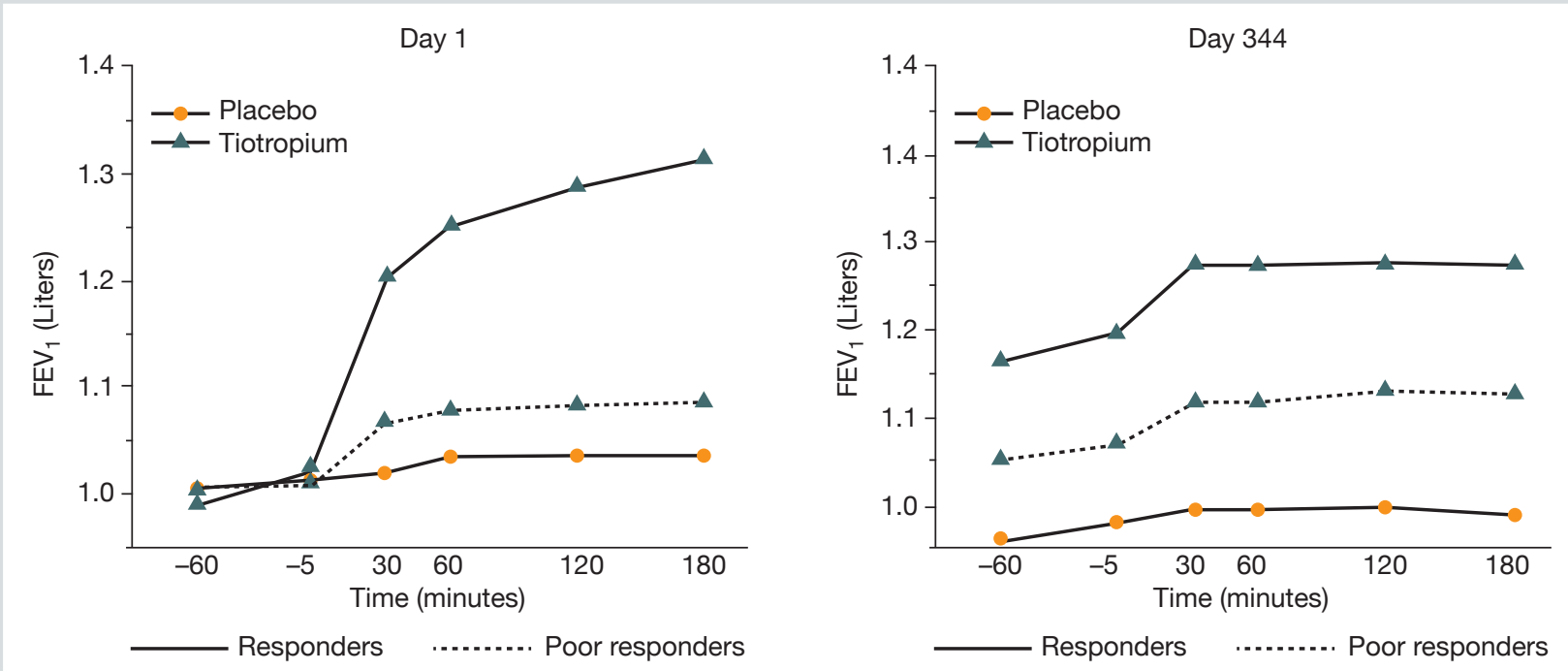

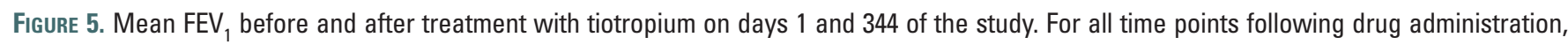
tiotropium significantly $(p<0.001)$ improved lung function in both the first-day good and poor tiotropium responders, but the magnitude of the response on day 344 was substantially smaller in the poor than in the good first-day responders (reproduced with permission from Tashkin DP et al. ${ }^{66}$ ).

$\mathrm{FEV}_{1}$ : forced expiratory volume in one second.

\section{DOES BRONCHODILATOR RESPONSIVENESS DEFINE A DISTINCT PHENOTYPE OF CHRONIC
OBSTRUCTIVE PULMONARY DISEASE?}

A COPD phenotype is defined by observable features that distinguish subgroups of patients from other subgroups in relation to clinically meaningful outcomes. A problematic challenge in addressing the question whether bronchodilator responsiveness defines a distinct COPD phenotype arises from the fact that significant responsiveness to a bronchodilator in any given patient with COPD (i.e., an improvement of $\geq 12 \%$ and $\geq 200 \mathrm{ml}$ over the pre-bronchodilator value) often changes over time ${ }^{1}$. Albert et al. ${ }^{45}$ attempted to circumvent this problem by comparing the relationship of 227 consistently responsive with 1362 consistently nonresponsive patients to clinical outcomes using data from the 3-year observational study Evaluation of COPD Longitudinally to Identify Predictive Surrogate End-points (ECLIPSE). Using logistic regression, they failed to find any significant difference between these two reversibility subgroups with regard to mortality, hospitalisation for a COPD exacerbation or withdrawal from the study ${ }^{45}$. On the other hand, they did observe a significantly greater occurrence of frequent moderate to severe exacerbations $(\geq 2 / y r)$ in the non-reversible subgroup after adjusting for age, sex, smoking status and BMI. However, this difference disappeared after adjustment for the pre-bronchodilator $\mathrm{FEV}_{1}$ percentage predicted, likely as a result of the fact that $\mathrm{FEV}_{1}$ reversibility diminishes with increasing airflow obstruction $^{10,11}$, as already stated, while the proportion of frequent exacerbators increases with the severity of obstruction ${ }^{67}$. 
A related phenotypic consideration is the question whether acute bronchodilator responsiveness predicts the subsequent course of COPD as defined by the annual rate of decline in lung function. In patients with initially mild-to-moderate airflow obstruction participating in the LHS, acute bronchodilator responsiveness at baseline did not predict the subsequent decline in $\mathrm{FEV}_{1}$ over 11 years of follow-up ${ }^{68}$. In the ECLIPSE cohort, as reported by Vestbo et al. ${ }^{69}$, those with bronchodilator reversibility at baseline had a mean rate of $\mathrm{FEV}_{1}$ decline over 3 years that was $17.4 \mathrm{ml} / \mathrm{yr}$ greater than the mean rate of decline in the entire cohort ( $33 \pm 2 \mathrm{ml} / \mathrm{yr}$ ). However, the annual rate of decline in $\mathrm{FEV}_{1}$ in COPD patients has been shown to be influenced by the baseline severity of airflow obstruction such that those with moderate obstruction $\left(\mathrm{FEV}_{1}, 50-79 \%\right.$ predicted) exhibit the most rapid decline, the rate of which decreases progressively in those with more severe obstruction ${ }^{60}$. Consequently, it is not unlikely that the more rapid rate of decline observed in the ECLIPSE subjects with positive reversibility was influenced by the fact that their mean baseline $\mathrm{FEV}_{1}$ was substantially higher than that in the subgroup without reversibility at baseline. The annual decline in $\mathrm{FEV}_{1}$ in patients with COPD is remarkably heterogeneous ${ }^{68}$ and is influenced most strongly by smoking status ${ }^{47}$, as well as by airway reactivity to methacholine ${ }^{70}$, the degree of airflow obstruction ${ }^{60}$, the presence of clinically significant emphysema on thoracic $\mathrm{HRCT}^{69}$ and the level of Clara cell protein (CC) 16 in blood ${ }^{69-71}$. On top of these influences, it is unlikely that the acute response to a bronchodilator has any useful prognostic utility in predicting the course of COPD as reflected by the trajectory of changes in lung function.

\section{CONCLUSIONS}

It is not entirely clear whether measuring the acute response to a bronchodilator in COPD truly matters depending on what aspect of COPD is under consideration. Defining a positive or significant bronchodilator response in accordance with the ATS/ERS recommendations is confounded by the considerable temporal variability of a positive or negative response in individual patients. While fulfilling the definition of COPD currently requires measurement of the post-bronchodilator $\mathrm{FEV}_{1} / \mathrm{FVC}$ ratio, it has become increasingly evident that a significant proportion of smokers without obstruction so defined have chronic respiratory symptoms and other COPD-like features. Since the majority of patients with COPD respond positively to a bronchodilator at any point in time, bronchodilator reversibility is not a reliable feature for distinguishing between asthma and COPD, unless the response is particularly marked. While the severity of airflow obstruction is defined by the post-bronchodilator $\mathrm{FEV}_{1}$ percentage predicted in accordance with the GOLD report, this categorization is no longer taken into account in the most recent GOLD treatment algorithm recommending preferred options for treatment with different classes of drugs ${ }^{14}$. Although most studies of the impact of different interventions on the progression of COPD now rely on the post- rather than the pre-bronchodilator $\mathrm{FEV}_{1}$ to track the course of the disease, use of the pre-bronchodilator $\mathrm{FEV}_{1}$ produces slopes of decline that are not too dissimilar and also simplifies the design of population-based observational studies. The lack of a short-term response to a bronchodilator does not preclude long-term effectiveness of maintenance bronchodilator 
therapy, although it does predict a generally lesser magnitude of the response in the longterm. Bronchodilator responsiveness does not appear to define a distinct phenotype of COPD or predict most clinically meaningful outcomes.

While the aforementioned observations suggest that the response to a bronchodilator may not matter much, there may be some practical utility in routinely measuring lung function after a bronchodilator for comparison with previous post-bronchodilator values to obviate confounding of spirometry results by variable times since the last bronchodilator medication was used prior to testing. In addition, post-bronchodilator spirometry might be useful to estimate the maximum or "ceiling" lung function that patients are capable of attaining as a goal to strive to achieve with pharmacotherapy, as well as to obtain some sense of the expected magnitude of benefit from maintenance bronchodilator medication ${ }^{62,63,65}$. In this practical regard, measuring the response to a bronchodilator may matter.

\section{CONFLICTS OF INTEREST}

Dr. Tashkin reports personal fees from Boehriinger-Ingelheim, personal fees from AstraZeneca, personal fees from Sunovion and personal fees from Theravance/Innoviva, outside the submitted work.

\section{REFERENCES}

1. Calverley PM, Burge PS, Spencer S et al. Bronchodilator reversibility testing in chronic obstructive pulmonary disease. Thorax. 2003;58:654-8.

2. Hanania NA, Celli BR, Donohue JF, Martin UJ. Bronchodilator reversibility in COPD. Chest 2011;140:1055-63.

3. Pellegrino R, Viegi G, Brusasco et al. Interpretative strategies for lung function tests. Eur Respir J. 2005;26:948-968.

4. Tashkin DP. Measurement and Significance of the Bronchodilator Response. In: BRONCHODILATORS: THEORY AND PRACTICE, Jenne JW editors.
Lung Biology in Health and Disease series, Lenfant C, editors. Marce Dekker, Inc., New York, NY, 1987.

5. Albert P, Agusti A, Edwards L et al. Bronchodilator responsiveness as a phenotypic characteristic of established chronic obstructive pulmonary disease. Thorax. 2012;67:701-8.

6. Donohue JF. Therapeutic responses in asthma and COPD. Bronchodilators. Chest. 2004. 126;125S-137S

7. Dorinsky PM, Reisner C, Ferguson GT et al. The combination of ipratropium and albuterol optimizes pulmonary function testing in patients with COPD. Chest. 1999; 115:966-71.

8. Konno S, Makita H, Hasegawa $\mathrm{M}$ et al. Beta2-adrenergic receptor polymorphisms as a determinant of preferential bronchodilator responses to beta2-agonist and anticholinergic agents in Japanese patients with chronic obstructive pulmonary disease. Pharmacogenetics and Genomics 2011;21:687-93.

9. Scanlon PD, Connett JE, Waller LA et al. Smoking cessation and lung function in mild-to-moderate chronic obstructive pulmonary disease: The Lung Health Study. Am J Respir Crit Care Med. 2000;161:381-90.

10. Tashkin DP, Celli B, Decramer M et al. Bronchodilator responsiveness in patients with COPD. Eur Respir J 2008;31:742-50.

11. Celli B, Tashkin DP, Rennard SI et al. Bronchodilator responsiveness and onset of effect with budesonide/formoterol pMDI in patients with COPD. Respir Med. 2011;105:1176-88.

12. Newton MF, O'Donnell DE, Forkert L. Response of lung volumes to inhaled salbutamol in a large population of patients with severe hyperinflatioin. Chest. 2002;121:1042-50.

13. O'Donnell DE, Lam M and Webb KA. Spirometric correlates of improvement in exercise performance after anticholinergic therapy in chronic obstructive pulmonary disease. Am J Respir Crit Care Med 1999;160:542-9.

14. Global Initiative for Chronic Obstructive Lung Disease. Global strategy for the diagnosis,management, and prevention of chronic obstructive pulmonary disease (2017 Report). 2017.

15. Mannino DM, Buist SA, Vollmer WM. Chronic obstructive pulmonary disease in the older adult: what defines abnormal lung function. Thorax. 2007;62:237-41.

16. Swanney MP, Ruppel G, Enright PL et al. Using the lower limit of norma for the FEV1/FVC ratio reduces the misclassification of airway obstruction. Thorax. 2008;63:1046-51.

17. Vollmer WM, Gislason T, Burney P et al. Comparison of spirometry criteria for the diagnosis of COPD: results from the BOLD study. Eur Respir J. 2009; 588-97.

18. Quanjer PH. Correctly defining criteria for diagnosing chronic obstructive pulmonary disease matters. Am J Respir Crit Care Med. 2014;189:230.

19. Mannino DM. Defining chronic obstructive pulmonary disease.... and he elephant in the room. Eur Respir J. 2007;30:189-90.

20. Johannessen A, Omenaas ER, Bakke PS et al. Implications of reversibility testing on prevalence and risk factors for chronic obstructive pulmonary disease: a community study. Thorax. 2005;60:842-7.

21. Mannino DM, Doherty DE, Buist S. A Global Initiative on Obstructive Lung Disease (GOLD) clasification of lung disease and mortality: findings from the Atherosclerosis Risk in Communities (ARIC) study. Respir Med. 2006 100:115-22

22. Staven K, Aaser E, Sandvik L et al. Lung function, smoking and mortality in a 26-year follow-up of healthy middle-aged males. Eur Respir J. 2005;25: 618-25.

23. Purdue MP, Gold L, Jarvholm B et al. Impaired lung function and lung cancer incidence in a cohort of Swedish construction workers. Thorax. 2007;62:51-6.

24. Tilert T, Dillon C, Paulose-Ram R et al. Estimating the U.S. prevalence of chronic obstructive pulmonary disease using pre- and post-bronchodilator spirometry: the National Health and Nutrition Examination Survery (NHANES) 2007-2010. Respir Research. 2013;14:103.

25. Mannino DM, Diaz-Guzman E, Buist S. Pre- and post-bronchodilator lung function as predictors of mortality in the Lung Health Study. Respir Res. 2011;12:136.

26. Fortis S, Eberlein M, Georgopoulos D et al. Predictive valuie of prebronchodilator spirometry for COPD features and outcomes. BMJ Open Respir Res. 2017;4:e000213. 
27. Bowler RP, Kim V, Regan E et al. Prediction of acute respiratory disease in current and former smokers with and without COPD. Chest. 2014;146: 941-50.

28. Regan EA, Lynch DA, Curran-Everett D et al. Clinical and radiographic disease in smokers with normal spirometry. JAMA Intern Med. 2015; 175:1539.

29. Woodruff PG, Couper D, Barr RG et al. Clinical significance of symptoms in smokers with preserved spirometry. N Engl J Med. 2016;374:1811-21.

30. Martinez CH, Murray S, Barr RG et al. Respiratory symptoms items from the COPD Assessment Test identify ever-smokers with preserved lung function at higher risk for poor respiratory outcomes. An analysis of the Subpopulations and Intermediate Outcome Measures in COPD Study Cohort. Ann Am Thorac Soc. 2017;14:636-42.

31. Global Initiative for Asthma and Global Initiative for Chronic Obstructive Pulmonary Disease. Diagnosis of diseases of chronic airflow limitation: Asthma, COPD and asthma-COPD overlap syndrome (ACOS). 2015. http:/ / www.ginasthma.org and http:/ / www.goldcopd.org.

32. Chipps BE, Tashkin DP, Uryniak T et al. Efficacy of budesonide/formoterol pressurized metered-dose inhaler in patients with mild to moderate asthma with and without fixed airflow obstruction. (Abstract) 2012 Annual Meeting of the American Academy of Allergy, Asthma and Immunology, Orlando, FL, March, 2012.

33. Tashkin DP, Chipps BE, Zhao S et al. Fixed airflow obstruction in asthma: A descriptive study of patient profiles and effect on treatment responses. J Asthma. 2014;51:603-9.

34. Tashkin DP, Moore GE, Trudo F et al. Assessment of consistency of fixed airflow obstruction status during budesonide/formoterol treatment and its effects on treatment options in patients with asthma. J Allergy Clin Immunol Pract. 2016;4:705-12.

35. Postma DS, Rabe KF. The asthma-COPD overlap syndrome. N Engl J Med. 2015;373;1241-9.

36. Desai M, Oppenheimer J, Tashkin DP. Asthma-chronic obstructive pulmonary disease overlap syndrome. What we know and what we need to find out. Ann Allergy Asthma Immunol. 2017;118:241-5.

37. Soler-Cataluna JJ, Cosio B, Izquierdo JL et al. Consensus document on the overlap phenotype COPD-asthma in COPD. Arch Bronconeumol. 2012;48: 331-7.

38. Koblizek V, Chlumsky J, Zindr V et al. Chronic obstructive pulmonary disease: Official diagnosis and treatment guidelines of the Czeck Pneumological and Phthisiological Society: a novel phenotypic approach to COPD with patient-oriented care. Biomed Pap Med FAac Univ Palacky Olomoouc Czech Repub. 2013;157:189-201.

39. Cosio BG, Soriano JB, Lopez-Campos JL et al. Defining the asthma-COPD overlap syndrome in a COPD cohort. Chest 2016;149: 45-52.

40. Sin DD, Miravitlles M, Mannino DM et al. What is asthma-COPD overlap syndrome? Towards a consensus definition from a round-table discussion. Eur Respir J. 2016;48:664-73.

41. Decramer M, Celli B, Tashkin DP et al. Clinical trial design considerations in assessing long-term functional impacts of tiotropium in COPD: The UPLIFT trial. COPD: Journal of Chron Obstruct Pulm Dis. 2004;1:303-12.

42. Wurst KE, Kelly-Reif K, Bushnell GA et al. Understanding asthma-chronic obstructive pulmonary disease overlap syndrome. Respir Med. 2016; 110:1-11.

43. Rabe KF, Hurd S, Anzueto A et al. Global strategy for the diagnosis, management, and prevention of chronic obstructive lung disease: GOLD executive summary. Am J Respir Crit Care Med. 2007;176: 532-55.

44. Vestbo J, Hurd SS, Agusti AG et al. Global strategy for the diagnosis, management, and prevention of chronic obstructive pulmonary disease. GOLD Executive summary. Am J Respir Crit Care Med. 2013;187:347-65.

45. Chen C-Z, Ou C-Y, Wang W-L et al. Using post-bronchodilator FEV1 is better than pre-bronchodilator FEV1 in evaluation of COPD severity. COPD. 2012;9:276-80

46. Fletcher C, Peto R. The natural history of chronic airflow obstruction. Br Med J. 1977;1:1645-8.

47. Anthonisen NR, Connett JE, Kiley JP et al. Effects of smoking intervention and the use of an inhaled anticholinergic bronchodilator on the rate of deline in $\mathrm{FEV}_{1}$ : The Lung Health Study. JAMA. 1994;272:1497-1505.
48. Lung Health Study Research Group, Wise R, Connett J, Weinmann G et al. Effect of inhaled triamcinolone on the decline in pulmonary function in chronic obstructive pulmonary disease. N Engl J Med. 2000;343:1902-9.

49. Pauwels RA, Lofdahl CG, Laitinen LA et al. Long-term treatment with inhaled budesonide in persons with mild chronic obstructive pulmonary disease who continue smoking. N Engl J Med. 1999;340:1948-53.

50. Vestbo J, Sorensen T, Lange P et al. Long-term effect of inhaled budesonide in mild and moderate chronic obstructive pulmonary disease: a randomised controlled trial. Lancet. 1999;353:1819-23.

51. Burge PS, Calverley PMA, Jones PW et al. Randomised, double blind, placebo controlled study of fluticasone propionate in patients with moderate to severe chronic obstructive pulmonary disease: the ISOLDE trial. BMJ. 2000;320:1297-1303.

52. Decramer M, Rutten-van Moken M, Dekhuijzen PNR et al. Effects of N-acetylcysteine on outcomes in chronic obstructive pulmonary disease: a randomized placebo-controlled trial. Lancet 2005;365;1552-60.

53. Celli BR, Thomas NE, Anderson JA et al. Effect of pharmacotherapy on rate of decline of lung function in chronic obstructive pulmonary disesase: results from the TORCH study. Am J Respir Crit Care Med 2008;178:332-8.

54. Vestbo FJ, Anderson JA, Brook RD et al. Fluticasone furoate and vilanterol and survival in chronic obstructive pulmonary disesasewith heightened cardiovascular risk (SUMMIT): a double-blind randomised controlled trial Lancet. 2016;387:1817-26.

55. Lapperre TS, Snoeck-Stroband JB, Gosman MM et al. Effect of fluticasone with and without salmeterol on pulmonary outcomes in chronic obstructive pulmonary disease: a randomized trial. Ann Intern Med. 2009;151:517-27.

56. Tashkin DP, Wang H-J, Halpin D et al. Comparison of the variability of the annual rates of change in $\mathrm{FEV}_{1}$ determined from serial measurements of the pre- versus post-bronchodilator $\mathrm{FEV}_{1}$ over 5 years in mild to moderate COPD: Results of the Lung Health Study. Respir Res. 2012;13:70.

57. Tashkin DP, Li N, Halpin D et al. Annual rates of change in pre- vs post-bronchodilator FEV1 and FVC over 4 years in moderate to very severe COPD. Respir Med. 2013;107:1904-11.

58. Tashkin DP, Li N, Kleerup E et al. Acute bronchodilator responses decline progressively over 4 years in patients with moderate to very severe COPD. Respir Res. 2014;5:102.

59. Anthonisen NR, Wright EC, and the IPPB Trial Group. Bronchodilator response in chronic obstructive pulmonary disease. Am Rev Respir Dis. 1986;133:814-9.

60. Tantucci C, Modina D. Lung function decline in COPD. Int J Chron Obstruct Pulmon Dis. 2012;7:95-9.

61. Hogg JC, Chu F, Utokaparch S et al. The nature of small airways obstruction in chronic obstructive pulmonary disease. N Engl J Med. 2004;350:2645-53.

62. Turner JM, Mead J, Wohl ME. Elasticity of human lungs in relation to age. J Appl Physiol 1968;25:664-71.

63. Mahler DA, Donohue JF, Barbee RA et al. Efficacy of salmeterol xinafoate in the treatment of COPD. Chest. 1999;115:957-65.

64. Rennard SI, Anderson W, ZuWallack R et al. Use of a long-acting inhaled $\beta 2$-adrenergic agonist, salmeterol xinafoate, in patients with chronic obstructive pulmonary disease. Am J Respir Crit Care Med. 2000;163:1087-92.

65. Cazzola M, Vinciguerra A, DiPerna F et al. Early reversibility to salbutamol does not always predcit bronchodilation after salmeterol in stable chronic obstructive pulmonary disease. Respiratory Medicine. 1998;92:1012-6.

66. Tashkin D, Kesten S. Long-term treatment benefits with tiotropium in COPD patients with and without short term bronchodilator responses. Chest. 2003;123:1441-9.

67. Hurst JR, Vestbo J, Anzueto A et al. Susceptibility to exacerbation in chronic obstructive pulmonary disease. N Engl J Med 2010;363:1128-38.

68. Anthonisen NR, Lindgren PG, Tashkin DP et al. Bronchodilator response in the lung health study over 11 years. Eur Respir J 2005;26;45-51.

69. Vestbo J, Edwards LD, Scanlon PD et al. Changes in forced expired volume in 1 second over time in COPD. N Engl J Med 2011;365:1184-93.

70. Tashkin DP, Altose MD, Connett JE et al. Methacholine reactivity predicts changes in lung function over time in smokers with early Chronic Obstructive Pulmonary Disease. Am J Respir Crit Care Med.1996;153:1802-11.

71. Park HY, Churg A, Wright J et al. Club cell protein 16 and disease progression in chronic obstructive pulmonary disease (COPD). Am J Respir Crit Care Med. 2013;188:1413-9. 